\title{
Clinical validation of the nursing diagnosis Risk for Aspiration among patients who experienced a cerebrovascular accident ${ }^{1}$
}

\author{
Tahissa Frota Cavalcante ${ }^{2}$ \\ Thelma Leite de Araújo ${ }^{3}$ \\ Rafaella Pessoa Moreira ${ }^{4}$ \\ Nirla Gomes Guedes ${ }^{5}$ \\ Marcos Venicios de Oliveira Lopes ${ }^{3}$ \\ Viviane Martins da Silva ${ }^{6}$
}

\begin{abstract}
Objective: the study's objective was the clinical validation of the nursing diagnosis Risk for Aspiration among patients who experienced cerebrovascular accidents (CVA). Method: a prospective cohort study was conducted with 24 patients hospitalized due to a CVA. The instrument used to collect the data addressed the risk factors for respiratory aspiration, validated by concept analysis and by experts. Results: the most frequent risk factors for respiratory aspiration were: dysphagia (54.2\%) and impaired physical mobility (41.7\%). The prevalence of the nursing diagnosis Risk for Aspiration was $58.3 \%$ and the prevalence of respiratory aspiration over the span of 48 hours (monitoring period) was $37.5 \%$. Risk factors for dysphagia and impaired physical mobility were significantly associated with respiratory aspiration. Conclusion: the risk factors dysphagia and impaired physical mobility are good predictors of the nursing diagnosis Risk for Aspiration. This study contributed to improving the NANDA-I Taxonomy and the systematization of the nursing process.
\end{abstract}

Descriptors: Nursing; Nursing Diagnosis; Respiratory Aspiration; Stroke.

\footnotetext{
1 Paper extracted from Doctoral Dissertation "Validação do diagnóstico de enfermagem Risco de aspiração em pacientes com acidente vascular cerebral" presented to Universidade Federal do Ceará, Brazil.

2 PhD, Assistant Professor, Curso de Enfermagem, Universidade Regional do Cariri, Brazil.

${ }^{3}$ PhD, Associate Professor, Curso de Enfermagem, Universidade Federal do Ceará, Brazil.

${ }^{4}$ PhD, Professor, Universidade de Fortaleza, Brazil. Professor, Faculdade Católica Rainha do Sertão, Brazil.

${ }^{5}$ PhD, Professor, Curso de Enfermagem, Faculdade Integrada do Ceará, Brazil. RN, Prefeitura Municipal de Fortaleza, Brazil.

${ }^{6}$ PhD, Adjunct Professor, Curso de Enfermagem, Universidade Federal do Ceará, Brazil.
}

Corresponding Author:

Tahissa Frota Cavalcante

Universidade Regional do Cariri

Rua Capitão Justino Ferreira Ramos, 230, Casa 02

Lagoa Redonda

CEP: 60844-025, Fortaleza, CE, Brasil

E-mail: tahissa@ig.com.br 


\title{
Validação clínica do diagnóstico de enfermagem "risco de aspiração" em pacientes com acidente cerebrovascular
}

Objetivo: o estudo teve por objeto a validação clínica do diagnóstico de enfermagem "risco de aspiração" em pacientes com acidente cerebrovascular. Método: estudo de coorte prospectivo, desenvolvido com 24 pacientes internados, para o tratamento do acidente cerebrovascular agudo. O instrumento utilizado para a coleta de dados continha os fatores de risco para a aspiração respiratória, validados por análise de conceito e por especialistas. Resultados: os fatores de risco para aspiração respiratória mais presentes nos pacientes foram: disfagia $(54,2 \%)$ e mobilidade corporal diminuída $(41,7 \%)$. A prevalência do diagnóstico de enfermagem "risco de aspiração" foi de 58,3\% e a prevalência em 48 horas (tempo de acompanhamento) da aspiração respiratória foi de $37,5 \%$. Os fatores de risco disfagia e mobilidade corporal diminuída apresentaram associação estatisticamente significativa com a aspiração respiratória. Conclusão: os fatores de risco disfagia e mobilidade corporal diminuída são bons preditores para o diagnóstico de enfermagem "risco de aspiração". Este trabalho possibilitou contribuir para o aperfeiçoamento da Taxonomia da NANDA-I e, por conseguinte, da linguagem da sistematização da assistência de enfermagem.

Descritores: Enfermagem; Diagnóstico de Enfermagem; Aspiração Respiratória; Acidente Vascular Cerebral.

\section{Validación clínica del diagnóstico de enfermería riesgo de aspiración en pacientes con accidente cerebrovascular}

\begin{abstract}
Objetivo: el estudio tiene como objetivo la validación clínica del diagnóstico de enfermería riesgo de aspiración en pacientes con accidente cerebrovascular. Método: un estudio de cohorte prospectivo desarrollado con 24 pacientes hospitalizados para el tratamiento del ictus agudo. El instrumento utilizado para la recolección de datos contiene los factores de riesgo de aspiración respiratoria, validado en el análisis conceptual y por expertos. Resultados: los factores de riesgo para aspiración respiratoria más presentes en los pacientes fueron: disfagia $(54,2 \%)$ y disminución de la movilidad física $(41,7 \%)$. La prevalencia del diagnóstico de enfermería riesgo de aspiración fue del 58,3\% y la prevalencia en 48 horas (el tiempo del seguimiento) de la aspiración respiratoria fue de 37,5\%. Los factores de riesgo disfagia y la disminución de la movilidad física se asociaron significativamente con la aspiración respiratoria. Conclusión: los factores de riesgo disminución de la movilidad física y disfagia son buenos predictores para el diagnóstico de enfermería riesgo de aspiración. Este trabajo permitió contribuir a la mejora de la taxonomía NANDA-I y, por lo tanto, el lenguaje de la sistematización de la atención de enfermería.
\end{abstract}

Descriptores: Enfermería; Diagnóstico de Enfermería; Aspiración Respiratoria; Accidente Cerebrovascular.

\section{Introduction}

This study's objective was to clinically validate the nursing diagnosis Risk for Aspiration in patients who had a cerebrovascular accident (CVA). An earlier study $^{(1)}$ presented an analysis of its concept and specialists validated the risk factors for the nursing diagnosis Risk for Aspiration in patients who had a CVA (stroke). The study reported that the risk factors for respiratory aspiration include: dysphagia, altered level of consciousness, impaired or absent cough reflex, other neurological disorders (e.g. brain injury or Alzheimer's disease), presbyphagia, use of gastrointestinal tubes, gastroesophageal reflux disease, impaired physical mobility, impaired or absent gag reflex, invasive procedures, such as advanced digestive endoscopy and videofluoroscopy, endotracheal intubation/ tracheostomy, and low headboard.

We kept the factors "the use of gastrointestinal tubes" and "endotracheal intubation/tracheostomy", even though they may seem redundant, because the literature differentiates them both. 
Knowledge concerning risk factors for respiratory aspiration in patients with a CVA is essential for nurses because the key element in the treatment of patients who have experienced a CVA in the acute and sub-acute phase is based on the prevention of complications, reduced hospitalization, mortality and hospital costs ${ }^{(2-3)}$.

The literature(4), however, reports that clinical predictors for the nursing diagnosis Risk for Aspiration are not well defined, while there are few studies addressing the clinical validation of this nursing diagnosis.

Given this context, studies performing the clinical validation of risk factors for the nursing diagnosis Risk for Aspiration in patients who had a CVA are needed. It is important to note that the main objective of this validation process is to increase the validity of this diagnosis in NANDA-I Taxonomy II and provide tools for nurses to evaluate patients who have had a CVA and are at risk for aspiration.

\section{Methods}

This observational study was conducted in the CVA unit of a public general tertiary hospital, a referral center for the treatment of people with this pathology in the Northeast, Fortaleza, CE, Brazil.

The population was composed of patients with a diagnosis of a CVA hospitalized in the aforementioned unit. A total of 24 individuals were included in the study, based on the following criteria: a) being older than 18 years of age; b) having a medical diagnosis of a CVA; c) being in the acute phase of the CVA (up to 72 hours after the first symptoms); d) being sufficiently conscious and able to follow commands. Those who, in the first assessment, presented respiratory aspiration or related complications, such as aspiration pneumonia, pneumonitis, obstructed airways, or pulmonary embolism, as well as those who, at the time of data collection, presented some clinical life- threatening condition, were excluded.

A convenience sample was selected. The patients were allocated in the study at the time they were admitted in the cerebrovascular accident unit (initial assessment) and reassessed 48 hours after the first assessment. This period between the two assessments was established in accordance with the recommendations of researchers ${ }^{(2,5-6)}$, who stated that respiratory aspiration is a clinical condition that occurs within five days of the first signs and symptoms of a CVA during hospitalization.

Criteria for discontinuity included: a) patients transferred to other health facilities or discharged; $b$ ) patients who, at the time of data collection, presented life-threating clinical conditions. No patients were excluded.

Data were collected from June to August, 2011. The instrument to collect data was developed considering risk factors identified in the literature, while experts performed the face and content validation. This instrument addressed socio-demographic, clinical, and predictor variables, which are risk factors for respiratory aspiration among patients who had CVA.

We note that due to the impossibility of assessing the outcome of respiratory aspiration in patients with a diminished level of consciousness, we did not investigate risk factors in patients with altered consciousness in this study, or those with orotracheal intubation/tracheostomy, because these procedures involve sedation, altering one's level of consciousness. Additionally, the assessment of the risk factor "neurological disorders" is related to the severity of the CVA (bilateral or/and with rupture of the bridging veins hemorrhagic cerebrovascular accident) associated or not with prior conditions, such as brain injury or Alzheimer's disease.

This study's outcome variable was respiratory aspiration. The gold standard for the assessment of respiratory aspiration is videofluoroscopy. Due to a lack of specialized personnel and the equipment required to perform videofluoroscopy, we checked the clinical signs proposed in two studies $^{(7-8)}$ : dysphonia, dysarthria, abnormal gag reflex, abnormal voluntary cough, cough after swallowing, and voice change after swallowing. Two or more of six of these signs indicate respiratory aspiration. The studies ${ }^{(7-8)}$ supporting these clinical signs present specificity of $89 \%$ for the detection of respiratory aspiration when compared to the gold standard (videofluoroscopy).

After the patients were identified, the study's objectives were explained to the patients and/or their respective companions. After signing free and informed consent forms, a preliminary assessment was performed to see whether the patients had the respiratory aspiration condition or related complications (e.g. aspiration pneumonia, pneumonitis, obstructed airways, and pulmonary embolism). Data were collected through physical assessment and consultation of the patients' medical files. The physical assessment focused on the patient's airway tract, searching for signs indicating complications related to respiratory aspiration. Consultation of the patients' medical charts enabled the researcher to read medical assessments looking for 
medical diagnoses (aspiration pneumonia, pneumonitis and pulmonary embolism), as well as readings of $\mathrm{X}$-rays. After this preliminary assessment, those who met all the inclusion criteria were assessed in terms of socio-demographic, clinical and predictor variables (risk factors) by means of interviews, physical assessments, and consultation of their medical charts. After 48 hours from the first evaluation, the patients were assessed again to see whether respiratory aspiration had occurred. As already mentioned, the researcher performed this second assessment checking for any of the six clinical $\operatorname{signs}^{(7-8)}$.

An expert, who met the system's specific scores criteria $^{(9)}$, that is, she had an academic and professional background in the field of nursing diagnoses and care delivered to patients who experienced CVA, verified whether the studied patients presented the diagnosis Risk for Aspiration. The expert received, after the first assessment, a summary of the case of each patient with his/her socio-demographic data, clinical variables and risk factors for respiratory aspiration but was not informed whether the outcome (respiratory aspiration) was confirmed or not. The purpose of having the participation of an expert in providing the diagnosis (Nursing diagnosis Risk for Aspiration) was to make sure data would not be biased by the researcher who collected data, since she would be aware of those patients who had suffered respiratory aspiration during hospitalization.

Excel 2007 spreadsheets were used while statistical analysis was performed by the Statistical Package for the Social Sciences (SPSS). The numerical variables were presented as central tendency and dispersion and the Shapiro-Wilks' test was used to verify the normality/ symmetry of the numerical data.

The binomial test was used to analyze the association of nominal data. Odds Ratio (OR) was used to verify the magnitude of association. Tests of sensitivity and specificity, positive predictive value and predictive negative value were performed, considering $p<0.05$ for statistical significance, in the analysis of accuracy of risk factors for respiratory aspiration.

In accordance with the guidelines from Resolution 196/96, Brazilian National Council of Health concerning research involving human beings ${ }^{(10)}$, this study was submitted to and approved by the Ethics Research Committee at the Federal University of Ceará (Process No. 262/10).

\section{Results}

A total of 24 patients who had experienced a CVA were monitored and their socio-demographic profiles are presented in Table 1.

Table 1 - Characterization of socio-demographic data of patients who had CVA. Fortaleza, CE, Brazil, 2011 $(n=24)$

\begin{tabular}{|c|c|c|c|c|c|c|}
\hline \multirow{2}{*}{$\begin{array}{l}\text { Variables } \\
\text { Gender }\end{array}$} & \multicolumn{3}{|c|}{$\mathbf{N}$} & \multicolumn{3}{|c|}{$\%$} \\
\hline & \\
\hline Male & \multicolumn{3}{|c|}{14} & \multicolumn{3}{|c|}{58.3} \\
\hline Female & \multicolumn{3}{|c|}{10} & \multicolumn{3}{|c|}{41.7} \\
\hline Total & \multicolumn{3}{|c|}{24} & \multicolumn{3}{|c|}{100.0} \\
\hline \multicolumn{7}{|l|}{ Marital status } \\
\hline Partner & \multicolumn{3}{|c|}{18} & \multicolumn{3}{|c|}{75.0} \\
\hline No partner & \multicolumn{3}{|c|}{6} & \multicolumn{3}{|c|}{25.0} \\
\hline Total & \multicolumn{3}{|c|}{24} & \multicolumn{3}{|c|}{100.0} \\
\hline \multicolumn{7}{|l|}{ Origin } \\
\hline Capital & \multicolumn{3}{|c|}{15} & \multicolumn{3}{|c|}{62.5} \\
\hline Interior & \multicolumn{3}{|c|}{9} & \multicolumn{3}{|c|}{37.5} \\
\hline Total & \multicolumn{3}{|c|}{24} & \multicolumn{3}{|c|}{100.0} \\
\hline \multicolumn{7}{|l|}{ Occupation } \\
\hline Retired & \multicolumn{3}{|c|}{12} & \multicolumn{3}{|c|}{50.0} \\
\hline $\begin{array}{l}\text { Independent } \\
\text { professional }\end{array}$ & \multicolumn{3}{|c|}{6} & \multicolumn{3}{|c|}{25.0} \\
\hline Employed & \multicolumn{3}{|c|}{3} & \multicolumn{3}{|c|}{12.5} \\
\hline Unemployed & \multicolumn{3}{|c|}{2} & \multicolumn{3}{|c|}{8.30} \\
\hline Homemaker & \multicolumn{3}{|c|}{1} & & 4.20 & \\
\hline Total & & 24 & & & 100. & \\
\hline & Average & $\mathrm{SD}^{*}$ & Median & $\mathrm{P} 25^{\dagger}$ & $\mathrm{P} 75^{\ddagger}$ & $p$-value ${ }^{\S}$ \\
\hline Age & 63.17 & 13.34 & 62.0 & 49.0 & 75.0 & 0.097 \\
\hline Schooling & 4.63 & 4.18 & 4.50 & 0.0 & 8.0 & 0.001 \\
\hline $\begin{array}{l}\text { Family income } \\
\text { (salary) }\end{array}$ & 1.69 & 1.020 & 1.0 & 1.0 & 2.0 & 0.000 \\
\hline
\end{tabular}

As shown in Table 1, most individuals who suffered CVA were male $(58.3 \%)$, lived with a partner $(75 \%)$, were from the capital of the state of Ceará $(62.5 \%)$, and retired $(50 \%)$. They were 63.17 years old $(S D=13.34)$ on average, though $25 \%$ of the sample was up to 49 years old.

In regard to schooling and family income, these variables present an asymmetric distribution in the assessed group $(p<0.05)$. The individuals attended school for 4.5 years (median) and had a monthly family income of up to one times the minimum wage (median).

In terms of clinical characteristics, most of the group had the ischemic type of the disease (91.7\%) and it was the first episode (75\%). The patients were 
evaluated 72 hours (median) from the beginning of the first signs and symptoms.

The distribution of risk factors for the nursing diagnosis Risk for Aspiration and the nursing diagnosis per se among the studied patients are presented below.

Table 2 - Distribution of risk factors for the nursing diagnosis Risk for Aspiration identified in patients who had a CVA. Fortaleza, CE, Brazil, $2011(n=24)$

\begin{tabular}{|c|c|c|}
\hline Risk factor for respiratory aspiration & $\mathbf{N}$ & $\%$ \\
\hline \multicolumn{3}{|l|}{ Dysphagia } \\
\hline Present & 13 & 54.2 \\
\hline Absent & 11 & 45.8 \\
\hline \multicolumn{3}{|l|}{ Impaired or absent cough reflex } \\
\hline Present & 4 & 16.7 \\
\hline Absent & 20 & 83.3 \\
\hline \multicolumn{3}{|l|}{ Neurological disorders } \\
\hline Present & 3 & 12.5 \\
\hline Absent & 21 & 87.5 \\
\hline \multicolumn{3}{|l|}{ Presbyphagia } \\
\hline Present & 5 & 20.8 \\
\hline Absent & 19 & 79.2 \\
\hline \multicolumn{3}{|l|}{ Gastrointestinal tubes } \\
\hline Present & 2 & 8.3 \\
\hline Absent & 22 & 91.7 \\
\hline \multicolumn{3}{|l|}{ Gastroesophageal reflux } \\
\hline Present & 6 & 25 \\
\hline Absent & 18 & 75 \\
\hline \multicolumn{3}{|l|}{ Impaired physical mobility } \\
\hline Present & 10 & 41.7 \\
\hline Absent & 14 & 58.3 \\
\hline \multicolumn{3}{|l|}{ Impaired or absent gag reflex } \\
\hline Present & 7 & 29.7 \\
\hline Absent & 17 & 70.3 \\
\hline \multicolumn{3}{|l|}{$\begin{array}{l}\text { Invasive procedures such as endoscopy and } \\
\text { videofluoroscopy }\end{array}$} \\
\hline Present & 0 & 0 \\
\hline Absent & 24 & 100 \\
\hline \multicolumn{3}{|l|}{ Low headboard } \\
\hline Present & 3 & 12.5 \\
\hline Absent & 21 & 87.5 \\
\hline \multicolumn{3}{|l|}{ Nursing diagnosis Risk for Aspiration } \\
\hline Present & 14 & 58.3 \\
\hline Absent & 10 & 41.7 \\
\hline \multicolumn{3}{|l|}{ Respiratory aspiration } \\
\hline Present & 9 & 37.5 \\
\hline Absent & 15 & 62.5 \\
\hline
\end{tabular}

Therefore, except for the risk factors of endoscopy and videofluoroscopy, all other risk factors were observed in clinical practice, less than $50 \%$ in the sample, except for the first factor. The risk factors most frequently presented by those with the nursing diagnosis Risk for Aspiration were dysphagia and impaired physical mobility.
The prevalence of the nursing diagnosis Risk for Aspiration in individuals who had a CVA was $58.3 \%$ and the prevalence of respiratory aspiration over 48 hours (monitoring period) was $37.5 \%$.

Table 3 presents the estimates of association among risk factors for respiratory aspiration and the clinical outcome of respiratory aspiration.

Table 3 - Distribution of estimates of association among risk factors for respiratory aspiration and the clinical outcome of respiratory aspiration in patients who had a CVA. Fortaleza, CE, Brazil, 2011

\begin{tabular}{|c|c|}
\hline Risk factors for respiratory aspiration & $\begin{array}{l}\text { Respiratory } \\
\text { aspiration }\end{array}$ \\
\hline \multicolumn{2}{|l|}{ Dysphagia } \\
\hline p-value* & 0.001 \\
\hline $\mathrm{OR}^{+}$ & 16 \\
\hline \multicolumn{2}{|l|}{ Impaired or absent cough reflex } \\
\hline p-value & 0.097 \\
\hline OR & 7.00 \\
\hline \multicolumn{2}{|l|}{$\begin{array}{l}\text { Neurological disorders (e.g. brain trauma or } \\
\text { Alzheimer's disease) }\end{array}$} \\
\hline p-value & 0.275 \\
\hline $\mathrm{RC}$ & 4 \\
\hline \multicolumn{2}{|l|}{ Presbyphagia } \\
\hline p-value & 0.899 \\
\hline OR & 1.14 \\
\hline \multicolumn{2}{|l|}{ Gastrointestinal tubes } \\
\hline p-value & 0.006 \\
\hline OR & 0.31 \\
\hline \multicolumn{2}{|l|}{ Gastroesophageal reflux } \\
\hline $\mathrm{p}$-value & 0.233 \\
\hline OR & 0.25 \\
\hline \multicolumn{2}{|l|}{ Impaired physical mobility } \\
\hline p-value & 0.007 \\
\hline OR & 14 \\
\hline \multicolumn{2}{|l|}{ Impaired or absent gag reflex } \\
\hline $\mathrm{p}$-value & 0.095 \\
\hline $\mathrm{OR}$ & 5.2 \\
\hline \multicolumn{2}{|l|}{$\begin{array}{l}\text { Invasive procedures such as endoscopy and } \\
\text { videofluoroscopy }\end{array}$} \\
\hline $\mathrm{p}$-value & - \\
\hline OR & - \\
\hline \multicolumn{2}{|l|}{ Low headboard } \\
\hline p-value & 0.275 \\
\hline OR & 4 \\
\hline
\end{tabular}

The risk factors dysphagia and impaired physical mobility, assessed using Brunnstrom's Stages of Motor Recovery, presented statistically significant association with respiratory aspiration $(p=0.001$ and $p=0.007$, respectively). The patients who were exposed to the risk of dysphagia had a 16 times greater chance of developing respiratory aspiration when compared to those who did 
not present this risk factor. Those with impaired physical mobility had a 14 times greater chance of developing respiratory aspiration.
Table 4 and Figure 1 present the accuracy measures of risk factors evaluated for the nursing diagnosis Risk for Aspiration.

Table 4 - Distribution of accuracy measures of risk factors for the nursing diagnosis Risk for Aspiration in patients who experienced a CVA. Fortaleza, CE, Brazil, 2011

\begin{tabular}{|c|c|c|c|c|}
\hline Risk factors for respiratory aspiration & Sensitivity (\%) & Specificity (\%) & Positive predictive value (\%) & Negative predictive value (\%) \\
\hline Dysphagia & 66.6 & 88.8 & 90.9 & 61.5 \\
\hline Impaired or absent cough reflex & 93.3 & 33.3 & 70 & 75 \\
\hline Neurological disorders & 93.3 & 22.2 & 66.6 & 66.6 \\
\hline Presbyphagia & 80 & 22.2 & 63.1 & 40 \\
\hline Gastrointestinal tubes & 94.1 & 27.2 & 66.6 & 75 \\
\hline Gastroesophageal reflux & 66.6 & 11.1 & 55.5 & 16.6 \\
\hline Impaired physical mobility & 80 & 77.7 & 85.7 & 70 \\
\hline Impaired or absent gag reflex & 86.6 & 44.4 & 72.2 & 66.6 \\
\hline $\begin{array}{l}\text { Invasive procedures such as advanced } \\
\text { digestive endoscopy and videofluoroscopy }\end{array}$ & - & - & - & - \\
\hline Low headboard & 93.3 & 22.2 & 66.6 & 66.6 \\
\hline
\end{tabular}

The analysis of data presented in Table 4 revealed that most of the risk factors (impaired or absent cough reflex, neurological disorders, presbyphagia, the use of gastrointestinal tubes, impaired or absent gag reflex, and low headboard) obtained high sensitivity values (above $80 \%$ ) with, however, low specificity values (below $60 \%$ ). The reduced number of studied patients $(n=24)$ may partially explain this fact.
Even thought the risk factor dysphagia presented an average sensitivity value $(66.6 \%)$, it was a risk factor of high specificity for the nursing diagnosis Risk for Aspiration $(88.8 \%)$, with a positive predictive value of $90.9 \%$. The risk factor impaired physical mobility was the only risk factor for respiratory aspiration that presented high sensitivity, specificity, and positive and negative predictive values for the nursing diagnosis Risk for Aspiration.

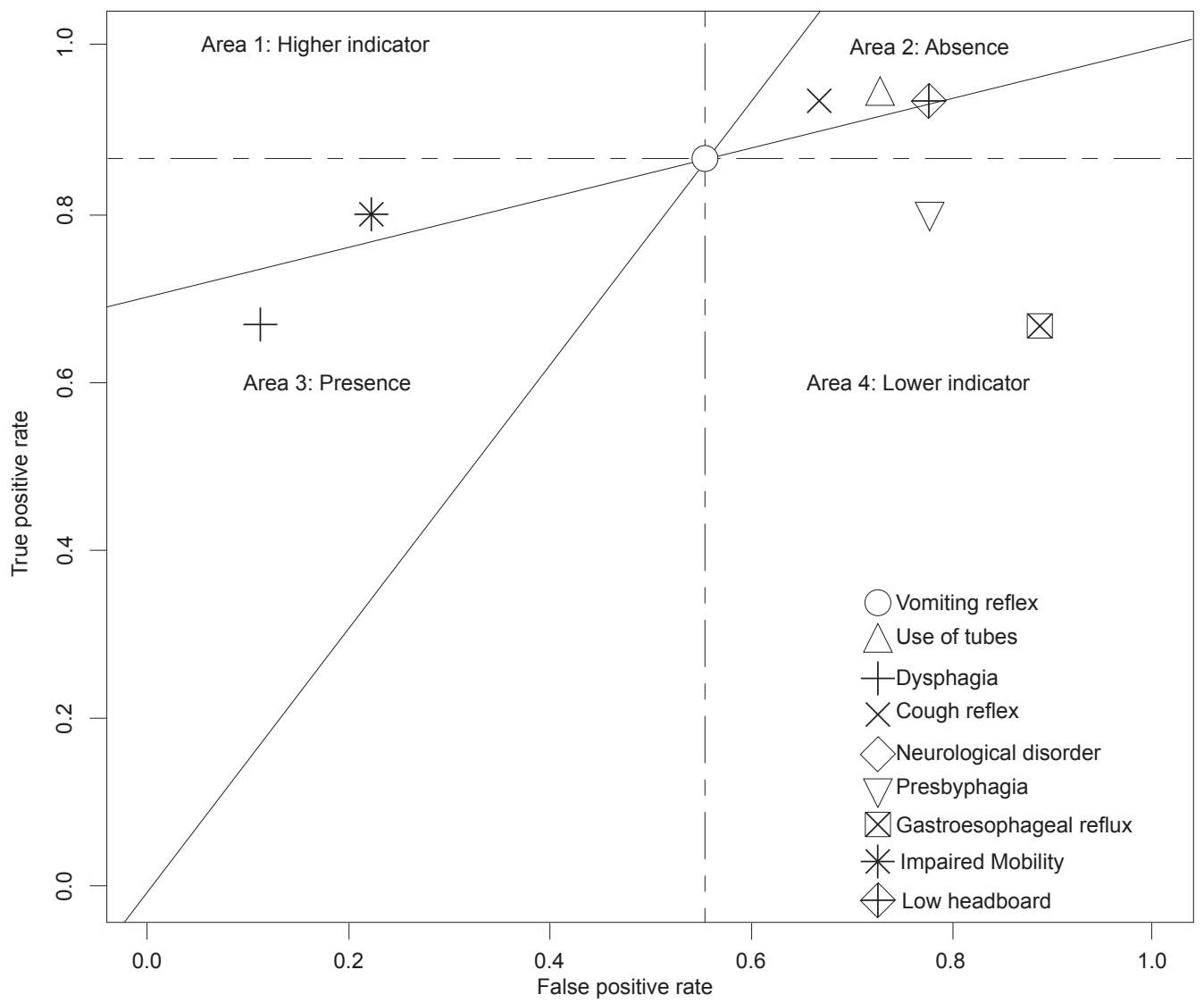

Figure 1 - Presentation of false positive and negative values of risk factors for respiratory aspiration when compared to the risk factor impaired or absent gag reflex. Fortaleza, CE, Brazil, 2011 
According to the data presented in Figure 1, we observe that when the risk factors dysphagia and impaired physical mobility are present, they predict the nursing diagnosis Risk for Aspiration (area 1 in the figure). When the risk factors impaired or absent cough reflex, use of gastrointestinal tubes, low headboard, and neurological disorders (brain injury, CVA, and Alzheimer's disease) are absent, there is indication that the nursing diagnosis Risk for Aspiration is also absent (area 2 in the figure).

The risk factors gastroesophageal reflux and presbyphagia were considered unsatisfactory for the nursing diagnosis Risk for Aspiration presented by patients who had had a CVA (area 4 in the figure).

\section{Discussion}

The analysis of the three first causes of death in 2009, according to the report Situação de Saúde no Estado do Ceará [Health Situation in the Ceará State] published in 2011(11), showed that diseases of the circulatory system were the primary cause of death, accounting for $30.2 \%(13,333)$ of all deaths, mainly among elderly individuals $(82 \% / 10,891)$, of both genders. Cerebrovascular diseases accounted for the highest number of deaths due to diseases in the circulatory system, followed by ischemic heart diseases and hypertensive diseases, in both genders.

In regard to gender, men were more prevalent in this study. Studies(12-14) report a slightly greater predominance of CVAs among the male population.

The average age of this study's individuals was 63.17 years old $(S D=13.34)$. A similar result was found in another study ${ }^{(15)}$. We note that, even though CVA is a disease that can occur at any age, its incidence increases as age advances and approximately doubles with each decade of life(16).

It is opportune, however, to consider the increased prevalence of cerebrovascular disease in the younger population, greatly affecting their social and economic spheres. In Brazil, the increase of hospitalizations due to CVAs among young individuals, between 15 and 34 years old, was $64 \%$ in men and $41 \%$ among women, from 1998 to 2007. Data from Brazilian Ministry of Health show that there were almost 8,000 hospitalizations in 2007 among individuals in this age group ${ }^{(17)}$.

The median number of years of schooling was 4.50 years; the median monthly family income was one times the minimum wage; and most patients were retired. Hence, the studied participants presented unfavorable socioeconomic conditions. Another study ${ }^{(12)}$ showed that most participants were either illiterate (39.1\%) or attended school for up to three years (20\%). Many researchers ${ }^{(18)}$ believe that the increased incidence of CVAs is related to a decreased socioeconomic level. The causes for such a relationship include: higher frequency of risk factors for cerebrovascular diseases, unfavorable psychosocial factors, and limited access to health services.

In relation to the prevalence of subtypes of CVAs, different results were found in another study ${ }^{(15)}$, because there was a balanced proportion between the ischemic type $(42.9 \%)$ and the hemorrhagic type (38.5\%).

The frequency of CVAs in the Brazilian population, according to different statistics, ranges from $53 \%$ to $85 \%$ of cases $^{(16)}$. It is important to note, however, that the high prevalence of the ischemic type compared to the hemorrhagic type found in this study may be explained, in part, by the established inclusion criteria (being conscious and capable of following commands) because the condition of patients with hemorrhagic CVA is more severe and they generally present an impaired level of consciousness.

Specifically in relation to the prevalence of dysphagia, this study was in agreement with data from various studies(6,8,19-20). The incidence of the nursing diagnosis Risk for Aspiration was similar to the one found in another study(15). In regard to respiratory aspiration, its incidence in patients who experienced a CVA is around $50 \%$ and approximately half of these patients experience silent aspiration ${ }^{(5)}$.

Because this study did not evaluate the presence of silent aspiration, the prevalence of respiratory aspiration presented by the assessed patients may be underestimated. It is a red flag to the health staff, especially the nursing staff, which needs to act early and efficiently to prevent this clinical condition.

Even though the risk factor impaired physical mobility, measured through Brunnstrom's Motor Recovery Stages, is not considered a risk factor for the nursing diagnosis Risk for Aspiration by the NANDA-I Taxonomy, it was found in almost $45 \%$ of the assessed patients and showed statistically significant association with respiratory aspiration.

In relation to the accuracy of clinical indicators for the nursing diagnosis Risk for Aspiration in patients who experienced a CVA, knowledge of the conditional probability of the presence or absence of the nursing diagnosis, based on clinical indicators, can help the nurses to infer and accurately diagnosis it. In this 
context, the study of the sensitivity and specificity of risk factors of the nursing diagnosis Risk for Aspiration permitted the evaluation of the importance of each risk factor for predicting Risk for Aspiration presented by patients who experienced a CVA.

In summary, the risk factors dysphagia and impaired physical mobility were good positive predictors of the nursing diagnosis Risk for Aspiration and also presented considerably high values of specificity for the studied diagnosis. In turn, the risk factors for the presence of gastroesophageal reflux, presbyphagia, and invasive procedures, such as advanced digestive endoscopy and videofluoroscopy, were not considered important risk factors for the nursing diagnosis Risk for Aspiration in patients who had a CVA.

\section{Conclusion}

The results indicated in the clinical validation showed that the risk factors dysphagia and impaired physical mobility are good predictors of the nursing diagnosis Risk for Aspiration among patients who had a CVA. The risk factors presbyphagia, gastroesophageal reflux, and invasive procedures, such as advanced digestive endoscopy and videofluoroscopy, were not specific and predictive of the studied diagnosis. Hence, further research addressing large populations in other contexts may confirm such a fact.

The risk factors for the nursing diagnosis Risk for Aspiration presented by patients who have experienced a CVA are: dysphagia, impaired or absent cough reflex, neurological disorders, gastrointestinal tubes, impaired physical mobility, impaired or absent gag reflex, and low headboard.

Limitations were faced during this study such as the fact that a single researcher collected data for clinical validation; the literature recommends a pair of researchers. Additionally, two risk factors "impaired consciousness" and "endotracheal intubation/ tracheostomy" were not verified because the assessment of six clinical signs indicating respiratory aspiration requires that the patient is alert. Finally, a reduced number of patients participated in the study $(n=24)$.

This study contributed to refining the nursing diagnosis Risk for Aspiration for individuals who experienced a CVA presented in the NANDA-I Taxonomy. The validation of this nursing diagnosis can ease the care phases: nursing history, nursing diagnosis, and intervention planning, in a specific and accurate manner to search for and analyze the Risk for Aspiration in patients who experienced a CVA. In this context, nurses with knowledge of all the risk factors for respiratory aspiration, can devise clinical protocols to prevent respiratory aspiration and more efficiently intervene with patients, whether independently or together with a multidisciplinary team.

\section{References}

1. Cavalcante TF. Validação do diagnóstico de enfermagem Risco de aspiração em pacientes com acidente vascular cerebral. 2011. [tese de doutorado]. Fortaleza: Departamento de Enfermagem, Universidade Federal do Ceará; 2011.

2. Summers D, Leonard A, Wentworth D, Saver JL, Simpson J, Spilker JA et al. Comprehensive overview of nursing and interdisciplinary care of to the acute ischemic stroke patient. Stroke 2009; 40:2911-2944.

3. Silva LTR, Laus AM, Canini SRMS, Hayashida M. Evaluation of prevention and control measures for ventilator-associated pneumonia. Rev. Latino-Am. Enfermagem. 2011;19(6):1329-36.

4. Wooldridge J, Herman JA, Garrison C, Haddock S, Massey J, Tavakoli AA. Validation study using the casecontrol method of the Nursing Diagnosis High Risk for Aspiration. Nurs Diag. 1998;9(1):5-13.

5. Falsetti P, Acciaci C, Palilla R, Bosi M, Carpinteri F, Zingarelli $A$ et al. Oropharyngeal Dysphagia after Stroke: incidence, diagnosis and clinical predictors in patients admitted to a Neurorehabilitation Unit. J Stroke Cerebrovasc Dis. 2009;18(5):329-35.

6. Trapl M, Enderle $P$, Nowotny $M$, Teuschl $Y$, Matz $K$, Dachenhausen A, Brainin M. Dysphagia bedisde screening for acute-stroke patients - the Gugging Swallowing Screen. Stroke. 2007;38:2948-52.

7. Daniels SK, Brailey K, Priestly DH, Herrington LR, Weisberg LA. Aspiration in patients with acute stroke. Arch Phys Med Rehabil. 1998;79(1):14-9.

8. Daniels SK, Ballo LA, Mahoney MC, Foundas AL. Clinical predictors of dysphagia and aspiration risk: outcome measures in acute stroke patients. Arch Phys Med Rehabil. 2000;81(8):1030-3.

9. Fehring RJ. The Fehring model. In: Carroll-Johnson RM, editor. Classification of nursing diagnosis: proceedings of the tenth conference. Philadelphia: JB Lippicott; 1994. p. 55-62.

10. Conselho Nacional de Saúde (BR). Resolução n०196/96. Decreto no 93.33 de janeiro de 1987. Estabelece critérios sobre pesquisa envolvendo seres humanos. Bioética. 1996;4(2):15-25. 
11. Secretaria de Saúde do Estado do Ceará (BR). Situação de Saúde no Ceará. Fortaleza (CE): SESA; 2011.

12. Falcão IV, Carvalho EMF, Barreto $\mathrm{KML}$, Lessa FJD, Leite VMM. Acidente vascular cerebral precoce: implicações para adultos em idade produtiva atendidos pelo Sistema Único de Saúde. Rev Bras Saúde Mater Inf. 2004;4(1):95-102

13. Cavalcante TF, Moreira RP, Araujo TL, Lopes MVO. Demographic Factors and Risk Indicators of Stroke: comparison between inhabitants of Fortaleza Municipal District and the National Profile. Rev. Latino-Am. Enfermagem. 2010;18(4):703-8.

14. Moreno VP, García Raso A, García Bueno MJ, Sánchez AS, Meseguer E, Mata R, Llhamas P. Factores de riesgo vascular en pacientes com ictus isquémico. Distribución según edad, sexo y subtipo de ictus. Rev. Neurol. 2008;46(10):593-8.

15. Cavalcante TF. Diagnósticos de enfermagem em pacientes internados por acidente vascular encefálico. 2008. [dissertação]. Fortaleza: Departamento de Enfermagem, Universidade Federal do Ceará; 2008.

16. André C. AVC Agudo. In: André C. Manual de AVC. Rio de Janeiro: Revinter; 2006. p. 37-51.

17. Ministério da Saúde (BR). Guia Metodológico de Avaliação e Definição de Indicadores. Doenças Crônicas Não Transmissíveis e Rede Carmen. Brasília: Editora MS; 2007.

18. Kurth T, Berger K. The socioeconomic stroke puzzle. Stroke 2007; 38:4-5.

19. Hammond CAS, Goldstein LB, Horner RD, Ying J, Gray L, Gonzalez L et al. Predicting aspiration in patients with ischemic stroke. Chest. 2009;135(3):769-77.

20. Taylor IC. Oropharyngeal dysphagia in long-term care: misperceptions of treatment efficacy. J Am Med Dir Assoc. 2008;9:523-31.

21. North American Nursing Diagnosis Association. Diagnósticos de enfermagem da NANDA: definições e classificação 2009-2011. Porto Alegre (RS): Artmed; 2010. 